\title{
AVALIAÇÃO DA DISPERSÃO NOS NIVEIS DE PREÇOS
}

\author{
Autor: César Augusto Tiburcio Silva \\ Doutorando em Contabilidade do Departamento de Contabilidade e \\ Atuaria da Faculdade de Economia , Administração e Contabilidade da USP. \\ Professor da Universidade de Brasília - UNB
}

\section{INTRODUÇÃO}

Este trabalho tem por objetivo discutir a influência da inflação nos relatórios contábeis. Em decorrência do contexto econômico brasileiro ser o de uma economia inflacionária, onde níveis de variação de preços mensais acima dos dois dígitos, são corriqueiros, este é um tema bastante discutido e debatido.

A contabilidade, como centro de informação por excelência, tem sido desafiada a propor soluções visando encontrar a melhor forma (ou as melhores formas) de apuração de resultados empresariais em ambientes inflacionários.

Particularmente no Brasil, a Lei 6.404/76 respondeu, de forma pioneira, com uma metodologia simplificada e, até certo ponto, eficiente. Mais recentemente, a Instrução CVM 64/87 introduziu a correção integral para as companhias abertas.

Recentemente, a discussão tem girado em torno de formas de aperfeiçoamento estes mecanismos, particularmente no que diz respeito ao indexador utilizado. Sabidamente, o índice que corrige as Demonstrações Contábeis não tem refletido a variação de preços na economia. Isto tem provocado um efeito devastador sobre a qualidade das informações, além de, na maior parte dos casos, gerar uma tributação adicional.

Entretanto, apesar da sadia discussão levantada no meio empresarial e acadêmico sobre a subestimação do indexador, um assunto ainda permanece fora de pauta.

Desde 1.986, com o plano cruzado I, o Pais tem passado por inúmeras reformas econômicas. Estas reformas tiveram como objetivo primordial a tentativa de eliminar ou reduzir o processo inflacionário então existente e foram executadas num período antecedido de aumento crescente nos preços.

Tradicionalmente tem sido afirmado que existiria uma correlação entre nível inflacionário e dispersão dos preços relativos. Em outras palavras, quanto maior a variação de preços, maior a distância entre as variações de preços específicas. Isto significa que um aumento na taxa inflacionária faz com que a inflação média perca sua expressão especifica. Estudar-se-ia em parte deste trabalho a relação entre nível inflacionário e dispersão nos preços, na pratica. Outro aspecto que será enfocado é o da relação dos níveis de inflação e os níveis econômicos recentes.

Inicialmente serão tecidas considerações rápidas sobre a influencia da variação de preços específicos na gestão financeira. Posteriormente são comentados aspectos concernentes aos índices de preços e os problemas decorrentes de sua utilização. Finalmente, na terceira parte do trabalho, trata-se da pesquisa prática realizada.

Considerações sobre a Influência nos Relatórios Contábeis

Caderno de Estudos no03, São Paulo, FIPECAFI - Março/1992 
Muito já se discutiu sobre a utilização de inflação própria numa empresa. Martins mostrou que o uso de indicador especifico não é indicado como substituto da inflação geral, como querem alguns autores. Em outra obra. Martins e Assaf (capitulo 10) apresentam a importância de se considerar preços específicos na administração financeira de uma empresa.

Com efeito se duas empresas apresentaram evolução real idêntica do faturamento, no período de 1986 a 1988, a análise de desempenho, a priori, seria a mesma. Entretanto se for informado que uma das empresas trabalha no ramo de extrativa mineral, e sabendo-se que os preços dos produtos industriais deste setor, neste período, apresentaram uma evolução que corresponde a metade da evolução do preço da economia, média pelo IGP-DI, a análise será diferente.

$\mathrm{Na}$ verdade, o processo inflacionário generalizado termina por encobrir as mudanças nos preços relativos, ou, em outros termos, as variações na curva da oferta e da demanda. No longo prazo, as variações especificas existentes em ambientes econômicos com inflação reduzida persiste.

A influencia destes fatos nos relatórios contábeis são marcantes. Apesar de utilizar a inflação geral como indexador das contas, a empresa deveria fornecer algum tipo de informação sobre o comportamento dos preços específicos. Uma vez que isso tem efeitos decisivos no desempenho da empresa.

Antes de analisar o comportamento dos preços específicos no Brasil nos últimos anos comenta-se, próximas linhas, alguns aspectos teóricos sobre a construção dos índices de preços.

\section{Algumas questões relativas aos índices de preços.}

Em geral o uso de índices ponderados para determinar variação de preço é feito através de duas metodologias. Á primeira, denominada de Laspeyres, tem como base de ponderação um período de tempo denominado de época básica. A segunda, índice de Paasche, usa como ponderação os preços e quantidades dos produtos no período de tempo atual. De uma outra forma, o índice Paasche terá mudança de peso quando muda a época básica. (Fonseca, 191). Poe este motivo, este último é tradicionalmente utilizado no calculo dos índices de preços.

A utilização dos índices de preços esta sujeita aos seguintes tipos de erros: de formula; de amostragem e de homogeneidade; de coleta; de mudança na economia; e de período. O erro de formula refere-se ao fato de que os tipos de índices de preços passiveis de serem utilizados, entre eles o índice laspeyres, não satisfazem as propriedades consideradas como fundamentais para um índice. (Fonseca, 191 - 193.)

O erro de amostragem decorre de se utilizar alguns produtos, em lugar de outros, na composição do índice. O erro de homogeneidade deriva da utilização de alguns produtos em lugar de todos os produtos em lugar de todos os produtos.

O erro de coleta mostrou-se particularmente importante no Brasil nos períodos de congelamento, como por exemplo, no Plano Cruzado. Neste período. Os produtos eram vendidos com ágio, não absorvido parcialmente pelas metodologias de preços. Outra situação em que o erro de coleta manifesta é na situação de desconto generalizado, onde a existência do desconto para venda a vista decorre da tentativa de antecipação, por parte dos agentes econômicos, a um possível congelamento.

A mudança na economia, decorrente de mudanças da oferta e da procura, afeta a qualidade dos índices. Assim, o aumento excessivo de um produto deve levar a uma redução na sua demanda. Entretanto, os índices de preços tradicionais captam somente o aumento de preço. Da mesma forma, e no sentido contrario, redução de preço deve levar a aumento do consumo: os índices de preços tradicionais só captam a variação de preço. A outra situação em que as mudanças afetam o índice e no caso de alterações tecnológicas. 
O erro decorrente do período diz respeito ao fato de que, em geral, os índices são calculados em períodos de tempo diferente do período ao qual se referem. Assim, um índice um índice para o mês atual é obtido por amostra de preços da segunda quinzena do mês anterior, até a primeira quinzena do mês atual em relação ao idêntico período interior.

A pesquisa e os Resultados

O primeiro passo na pesquisa foi determinar um índice de preços. A escolha recaiu sobre o índice da Fundação Getulio Vargas em virtude de sua acessibilidade. O índice de preços por atacado disponibilidade interna - IPA - DI foi o escolhido (coluna 4 da conjuntura Econômica). Acredita-se que a escolha do índice não afetou, substancialmente, as conclusões desta pesquisa.

Após a escolha do índice partiu-se para determinar a ponderação dos seus componentes. A obtenção dos pesos foi feita através da resolução de sistemas lineares. Com estes pesos é possível determinar a dispersão dos preços, através da variância, do desvio padrão e do coeficiente de variação do IPA - DI.

A evolução do IPA- DI e do desvio-padrão é apresentada nos gráficos 1. A relação entre as duas variáveis, medida através do coeficiente de correlação, é apresentada na tabela 1. Conforme pode ser notado, ao contrario do esperado inicialmente, essa relação apresenta-se, no período considerada baixa.

\section{Tabela 1}

\section{Variável}

$\mathrm{R} 2$

R2 ajustado

$\mathrm{F}$

SE

\section{Resultado}

\section{Obs: Ver Anexos}

A principal razão para este comportamento deve-se aos planos econômicos que impuseram, para os agentes econômicos, congelamentos nos seus preços. Conforme pode ser observado no gráfico 2 , nos períodos após os planos econômicos, o coeficiente de variação da inflação cresce substancialmente, apesar da redução nos níveis de preços.

No instante de congelamento, os preços dificilmente estarão em equilíbrio. Além disto, alguns setores tem maiores possibilidades de superar o congelamento, ao contrario de outros, que não escapam da rigidez das medidas econômicas.

Portanto, a dispersão dos preços aumenta com as conseqüências adivinhas da imposição de planos econômicos.

Outro período que provavelmente deve ocorrer aumento na dispersão é quando existe a flexibilidade dos preços, momento em que os setores com preços defasados tentam corrigi-los. Entretanto, a análise de tal questão fica dificultada porque, ao contrario dos planos econômicos, o "Descongelamento dos preços" não tem um momento claramente definido no tempo. A única exceção prática ocorreu no Plano Cruzado I conforme pode ser notado no coeficiente de variação de dezembro de 1986.

Ao usuário das informações contábeis cabe ressaltar atento a este problema. 


\section{INFLAÇÃO E MEDIDAS DE DISPERSÃO \\ BRASIL \\ 1986}

\begin{tabular}{|c|c|c|c|c|}
\hline PERIODO & Inflação & variancia & Desvio & $\mathrm{CV}$ \\
\hline $\mathrm{Abr} / 86$ & -1.46 & .97 & .98 & -67.43 \\
\hline Maio & .08 & .15 & .39 & 444.63 \\
\hline Jun & .38 & .61 & .78 & 208.64 \\
\hline Jul & .59 & .36 & .60 & 102.71 \\
\hline Ago & 1.34 & 1.46 & 1.21 & 90.34 \\
\hline set & .66 & .73 & .85 & 128.39 \\
\hline Out & 1.15 & 1.64 & 1.28 & 111.24 \\
\hline Nov & 2.13 & 4.09 & 2.02 & 94.92 \\
\hline Dez & 7.65 & 95.31 & 9.76 & 127.57 \\
\hline $\mathrm{Jan} / 87$ & 10.50 & 32.39 & 5.69 & 54.20 \\
\hline Fev & 10.36 & 72.22 & 8.50 & 82.04 \\
\hline Mar & 14.05 & 66.04 & 8.13 & 57.85 \\
\hline Abr & 20.99 & 91.36 & 9.56 & 45.55 \\
\hline Maio & 30.71 & 23.66 & 4.86 & 15.84 \\
\hline Jun & 26.26 & 23.45 & 4.84 & 18.44 \\
\hline Jul & 9.89 & 41.21 & 6.42 & 64.91 \\
\hline Ago & 3.72 & 11.73 & 3.43 & 92.10 \\
\hline set & 7.55 & 7.08 & 2.66 & 35.25 \\
\hline out & 11.67 & 3.51 & 1.87 & 16.05 \\
\hline Nov & 14.98 & 7.08 & 2.66 & 17.77 \\
\hline Dez & 16.05 & 21.95 & 4.68 & 29.20 \\
\hline $\mathrm{Jan} / 88$ & 18.39 & 27.86 & 5.28 & 28.71 \\
\hline Fev & 17.86 & 10.98 & 3.31 & 18.55 \\
\hline Mar & 17.52 & 8.61 & 2.94 & 16.75 \\
\hline Abr & 21.32 & 16.76 & 4.09 & 19.20 \\
\hline Maio & 19.27 & 1.90 & 1.38 & 7.16 \\
\hline Jun & 21.23 & 9.78 & 3.13 & 14.73 \\
\hline Jul & 22.25 & 3.74 & 1.93 & 8.69 \\
\hline Ago & 23.71 & 4.02 & 2.00 & 8.46 \\
\hline set & 26.15 & 7.97 & 2.82 & 10.80 \\
\hline out & 26.88 & 7.16 & 2.68 & 9.95 \\
\hline Nov & 27.59 & 13.22 & 3.64 & 13.18 \\
\hline Dez & 29.46 & 3.16 & 1.78 & 6.03 \\
\hline $\mathrm{Jan} / 89$ & 36.12 & 17.89 & 4.23 & 11.71 \\
\hline Fev & 10.74 & 37.36 & 6.11 & 56.92 \\
\hline Mar & 3.11 & 10.78 & 3.28 & 105.58 \\
\hline Abr & 4.88 & 22.28 & 4.72 & 96.62 \\
\hline Maio & 11.22 & 19.81 & 4.45 & 39.68 \\
\hline Jun & 25.42 & 35.86 & 5.99 & 23.56 \\
\hline Jul & 39.44 & 172.18 & 13.12 & 33.27 \\
\hline Ago & 36.73 & 126.00 & 11.23 & 30.50 \\
\hline Set & 41.41 & 78.22 & 8.84 & 21.36 \\
\hline out & 40.34 & 65.21 & 8.08 & 20.02 \\
\hline Nov & 44.32 & 9.38 & 3.06 & 6.91 \\
\hline Dez & 48.89 & 18.26 & 4.27 & 8.74 \\
\hline $\mathrm{Jan} / 90$ & 72.63 & 21.62 & 4.65 & 6.40 \\
\hline
\end{tabular}




\begin{tabular}{lrrrr} 
Fev & 73.99 & 61.82 & 7.86 & 10.63 \\
Mar & 82.04 & 57.72 & 7.60 & 9.26 \\
Abr & 9.98 & 27.31 & 5.23 & 52.38 \\
Maio & 9.93 & 191.30 & 13.83 & 139.27 \\
Jun & 7.32 & 15.48 & 3.93 & 53.73 \\
Jul & 11.57 & 12.57 & 3.55 & 30.64 \\
Ago & 12.95 & 4.58 & 2.14 & 16.53 \\
Set & 11.06 & 5.84 & 2.42 & 21.86 \\
Out & 14.59 & 5.53 & 2.35 & 16.11 \\
Nov & 18.43 & 14.81 & 3.85 & 20.88 \\
Dez & 15.00 & 20.51 & 4.53 & 30.20 \\
Jan/91 & 20.32 & 15.79 & 3.97 & 19.56 \\
Fev & 21.57 & 86.67 & 9.31 & 43.16 \\
Mar & 7.48 & 47.91 & 6.92 & 92.50 \\
Abr & 9.04 & 40.67 & 6.38 & 70.51 \\
Maio & 5.45 & 4.07 & 2.02 & 36.99 \\
\hline
\end{tabular}

\section{PROVISÃO PARA ENCARGOS SOCIAIS}

\section{INTRODUÇÃO}

E um conceito bastante intuitivo o de se associar determinado sacrifício ao resultados ou benefícios dele decorrentes. Sendo assim ao avaliar o resultado de determinada ação, deve-se considerar, em contrapartida, os custos para a sua realização.

"Toda despesa diretamente delineável com as receitas reconhecidas, em determinado período, com as mesmas deverá ser confrontada; os consumos ou sacrifícios de ativos (atuais ou futuros), realizados em determinado período e que não puderem ser associados a receita do período nem a dos períodos futuros, deverão ser descarregados como despesas do período em que ocorrem ..."(1)

Portanto, a apropriação dos custos ou despesas, seja de salários ou encargos sociais, deverá ser devidamente provisionada nos períodos em que ocorrer a efetiva contraprestação de serviços, ou seja, nos períodos de produção do empregado. Durante os períodos em que o empregado não permanecer à disposição da empresa, não deverá haver nenhuma apropriação.

\section{Férias}

Vejamos os lançamentos contábeis que deveriam ser efetivados pela entidade:

a) Mensalmente

Débito: Férias (Custo ou despesa operacional)

Crédito: Provisão para férias (passivo circulante)

Débito: Contribuições Sociais sem Férias (Custo ou despesa operacional)

Crédito: Provisão para Contribuições Sociais sobre Férias (Passivo Circulante):

Previdência Social

Fundo de Garantia

Seguro-Acidentes

b) Por ocasião da Concessão e Pagamentos das Férias

Débito: Provisão para Férias

Crédito: Caixa/Bancos

Debito: provisão para Contribuições Sociais sobre Férias

Crédito: Contribuições Sociais a Pagar (Passivo Circulante):

Providência Social 
Fundo de Garantia

Seguro-Acidentes

c) Por Ocasião do Recolhimento das Contribuições Sociais:

Débito: Contribuições Sociais a Pagar

Crédito Caixa/Bancos

\section{O Problema Fiscal}

O regulamento do imposto de renda (2) admite a constituição e a dedução, como custo ou Despesa Operacional, da provisão para férias, desde que se apure, na data do balanço, o valor real a que cada empregado faz jus aquela data, considerando:

a) A remuneração em valor

b) O numero de dias de férias a que cada empregado tem direito, de acordo com a seguinte tabela

\begin{tabular}{|c|r|r|r|r|}
\hline \multirow{2}{*}{$\begin{array}{l}\text { Ne de dias de } \\
\text { Faltas no Peri- } \\
\text { odo Aquisitivo }\end{array}$} & \multicolumn{2}{|c|}{ Ferias Normais } & \multicolumn{2}{|c|}{$\begin{array}{c}\text { Proporcionais } \\
\text { (por mês) }\end{array}$} \\
\cline { 3 - 6 } & Em dias & Em horas & Dias & Horas \\
\hline até 5 & 30 & 220 & 2,5 & 18,33 \\
até 14 & 24 & 176 & 2,0 & 14,67 \\
até 23 & 18 & 132 & 1,5 & 11,00 \\
até 32 & 12 & 88 & 1,0 & 7,33 \\
+ de 32 & 0 & 0 & 0 & 0 \\
\hline
\end{tabular}

Logo, é necessário verificar, ao término de cada período-base de apuração do imposto se houver ou não provisionamento além do limite.

Caso haja excesso, seu valor deverá ser oferecido à tributação através de ajuste do Lucro Liquido do Exercício, a ser registrado no Livro de Apuração do Lucro Real (LALUR) . 